\title{
Coupled Dynamic Analysis for the Riser-Conductor of Deepwater Surface BOP Drilling System
}

\author{
Kanhua Su $\left(\mathbb{D},{ }^{1,2}\right.$ Stephen Butt, ${ }^{2}$ Jianming Yang $\mathbb{D}^{2},{ }^{2}$ and Hongyuan Qiu $\mathbb{D}^{2}$ \\ ${ }^{1}$ School of Petroleum Engineering, Chongqing University of Science and Technology, Chongqing, China \\ ${ }^{2}$ Faculty of Engineering and Applied Science, Memorial University of Newfoundland, St. John's, NL, Canada \\ Correspondence should be addressed to Kanhua Su; sukanhua@126.com
}

Received 31 May 2017; Accepted 21 November 2017; Published 11 January 2018

Academic Editor: Yuri S. Karinski

Copyright (c) 2018 Kanhua Su et al. This is an open access article distributed under the Creative Commons Attribution License, which permits unrestricted use, distribution, and reproduction in any medium, provided the original work is properly cited.

\begin{abstract}
Deepwater surface BOP (surface blowout prevention, SBOP) drilling differs from conventional riser drilling system. To analyze the dynamic response of this system, the riser-conductor was considered as a beam with varied cross-sections subjected to loads throughout its length; then an equation of motion and free vibration of the riser-conductor string for SBOP was developed. The finite difference method was used to solve the equation of motion in time domain and a semianalytical approach based on the concept of section division and continuation was proposed to analyze free vibration. Case simulation results show that the method established for SBOP system natural frequency analysis is reasonable. The mode shapes of the riser-conductor are different between coupled and decoupled methods. The soil types surrounding the conductor under mudline have tiny effect on the natural frequency. Given that some papers have discussed the response of the SBOP riser, this work focused on the comparison of the dynamic responses on the wellhead and conductor with variable conditions. The dynamic lateral displacement, the bending moment, and the parameters' sensitivity of the wellhead and the conductor were analyzed.
\end{abstract}

\section{Introduction}

Several operators have developed surface BOP (surface blowout prevention, SBOP) drilling technology for deepwater drilling. SBOP drilling differs from a conventional riser drilling system: the BOP stack is located at the surface below the drill floor of the platform, not at the seabed. Another key difference is that the riser of the SBOP drilling system is designed to contain wellbore pressure, whereas a conventional drilling riser does not contain pressure. The SBOP drilling system can use smaller 2nd- or 3rdgeneration semisubmersible rigs for operation. Moreover, it has illustrated a considerable amount of day rate saving over traditional drilling methods using subsea BOP [1]. As presented in the IADC (International Association of Drilling Contractors) guidelines for SBOP from floating MODUs [2], the key components of the SBOP drilling system include the surface BOP stack, upper transition joint, casing riser, lower transition joint, seabed isolation device (SID), subsea wellhead, conductor, and casing strings.
Surface BOP is not a new concept, but it was extended into deepwater only a few years ago. Based on successful drilling campaigns in Asia, Shell extended its SBOP technology to the more demanding offshore operations in Brazil with the implementation of a SID. Unocal and Transocean pioneered the application of the SBOP from floating drilling units, which began in early 1996 in the relatively benign environment of Southeast Asia (Kozicz, 2006) [3]. The deepwater well 1-SHEL-14-RJS (block BM-C-10 in the Campos Basin, offshore Brazil) was successfully drilled in water depth of $2887 \mathrm{~m}$ by Shell in 2003 . The $339.7 \mathrm{~mm}$ size, P110 grade, and $35 \mathrm{Mpa}$ casing riser was adopted in this well (Brander et al., 2004) [4]. Total used the SBOP technique in $2000 \mathrm{~m}$ water depth on its Donggala block in Indonesia. For this SBOP drilling system, a $339.7 \mathrm{~mm}$ casing riser complete with specially designed fatigue enhanced connections was used (Simondin et al., 2004) [5]. In 2008, SBOP technology was implemented for both drilling and completion operations for the Parque das Conchas deepwater development in block BC10 offshore of Brazil. A dedicated $406.4 \mathrm{~mm}$, X80 grade, and 
$41 \mathrm{Mpa}$ high pressure riser replaced the marine riser in the SBOP system (Tarr et al., 2009) [6]. A compact deepwater drilling ship for SBOP operations was built (Claassen et al., 2010) [7].

Typical configurations of the casing riser include diameters of $273.1 \mathrm{~mm}, 339.7 \mathrm{~mm}$, and $406.4 \mathrm{~mm}$. At the top and bottom of the casing riser, heavy walled transition joints are required to distribute stresses [2]. Due to the small size of the casing riser, a $762.0 \mathrm{~mm}$ or smaller conductor is adopted to be jetted into the seabed as a support for the wellhead and other casing strings. Similar to a conventional riser, the high pressure casing riser is under complex forces imposed by vessel motions, waves, and current and soil interaction, which are transferred to the subsea wellhead and conductor.

Specialized computer programs are generally used to predict conventional riser's behavior under the designed conditions [8]. The motion equation of the riser is usually converted to a system of finite length elements using either a finite difference or a finite element technique. Botke (1975) used a derivation of the riser equations and finite difference method (FDM) of solution [9]. Gardner and Kotch (1976) described finite element method (FEM) applied to the riser [10]. Subsequently, many researchers have studied the dynamics of the deepwater drilling riser.

For the SBOP drilling system, the design loads include bending loads, coming from the riser, stress joint and wellhead above the mudline, and soil reaction below the mudline. IADC identified that the casing riser and conductor analysis should be conducted in a coupled manner [2]. As the loads on the bottom of the riser will be transferred to the wellhead and conductor, the coupled concept of riser and conductor is concerned [11]. King et al. (1993) developed a new approach to analyze the behavior of a drilling riser and conductor as a complete entity, and the FEM was used in his research [12]. Although FEM is able to represent more details of the riser including the connection points, the mesh should be carefully implemented with good modeling practices. Su et al. (2008) studied the stability of the subsea wellhead and the conductor bearing capacity in deepwater drilling and proposed a wellhead stability analysis method with FDM [13]. Yan et al. (2015) analyzed the wellhead stability problem in deepwater drilling using the pile element and nonlinear spring element of ANSYS [14]. Results show that the coupled method to analyze the conventional riser-conductor system is reasonable.

However, the casing riser analysis for the SBOP drilling system is conducted in accordance with API RP 16Q for the conventional riser. Some literatures discussed the dynamic behavior of the SBOP drilling riser. Morooka et al. (2008) presented a numerical simulation to estimate the riser behavior for a drilling system with surface BOP, but the research did not consider the coupling effect between the wellhead and conductor [15]. Dib et al. (2009) analyzed the fatigue lifetime of the SBOP riser in various modes of operation and also ignored the effect of the conductor [16]. For the SBOP riser-conductor system, as the transition joints replace the flex/ball joint, this allows for the consideration of the riserconductor as a beam with varied cross-sections subjected to loads throughout its length. Therefore, it is feasible to model the system considering the coupling between the riser and the conductor for the SBOP system and to solve the equations with FDM and other semianalytical methods.

In this paper, a coupled time-domain dynamic FDM method for the riser-conductor of the SBOP system is derived, and a semianalytic method is developed for the free vibration of riser-conductor. These methods are more convenient for the analysis coupled with the riser, SID, wellhead, and conductor of the deepwater SBOP drilling system.

\section{Equation of Motion of Riser-Conductor in Transverse Vibration for SBOP Drilling}

As the transition joints connect to the surface BOP and SID, there is no rotary joint on the riser-conductor for the SBOP system. Thus, the riser-conductor can be considered as a beam with varied cross-sections subjected to loads. The riser-conductor of the SBOP system is modeled as a variable section Euler-Bernoulli beam undergoing transverse vibration under axial force, as is shown in Figure 1(a). The forces acting on an element of the riser-conductor system of length $d x$ are shown in Figures 1(b) and 1(c).

2.1. Equation of Motion of Riser-Conductor System. By assuming (1) the riser-conductor is a Euler-Bernoulli beam, (2) the riser and casing string are both linear elastic, (3) the drilling string has no effect on its bending rigidity, and (4) the vessel, wave, current, and riser all move in a plane, then the riser can be modeled as a beam subjected to loads throughout its length with boundary conditions at the top and bottom ends.

According to the Euler-Bernoulli theory [17, 18], the equation of motion for the forced lateral vibration of the riserconductor system can be obtained as in

$$
\begin{aligned}
& \frac{\partial^{2}}{\partial x^{2}}\left[E(x) I(x) \frac{\partial^{2} y(x, t)}{\partial x^{2}}\right]+\frac{\partial}{\partial x}\left[P(x) \frac{\partial y(x, t)}{\partial x}\right] \\
& \quad+m(x) \frac{\partial^{2} y(x, t)}{\partial t^{2}}+c_{s}(x) \frac{\partial y(x, t)}{\partial t} \\
& \quad+k_{f}(x) y(x, t)=F(x, t),
\end{aligned}
$$

where $y$ is the lateral displacement of the riser-conductor system, $\mathrm{m} ; x$ is the depth coordinate as shown, $\mathrm{m} ; m$ is the riser-conductor system mass per unit length, $\mathrm{kg}$; $c_{s}$ is the riserconductor system damping coefficient, $\mathrm{N} \cdot \mathrm{s} / \mathrm{m} ; k_{f}$ is the riserconductor system stiffness, N/s; $E$ is Young's modulus of the riser-conductor system, $\mathrm{N} / \mathrm{m}^{2} ; I$ is the area moment of inertia of cross-section, $\mathrm{m}^{4}$; $P$ is the effective tension or compressive force on the riser-conductor, $\mathrm{N}$; and $F$ is the force on the riserconductor system, $\mathrm{N}$.

The external forces on the riser, SID, and wellhead can be computed using the Morison equation (American Petroleum Institute, 2001) [8]; this equation has been widely used in riser dynamic analysis. As the riser transfers its forces to the conductor and casing strings, the lateral force $q$ on the conductor and casing strings is zero. 


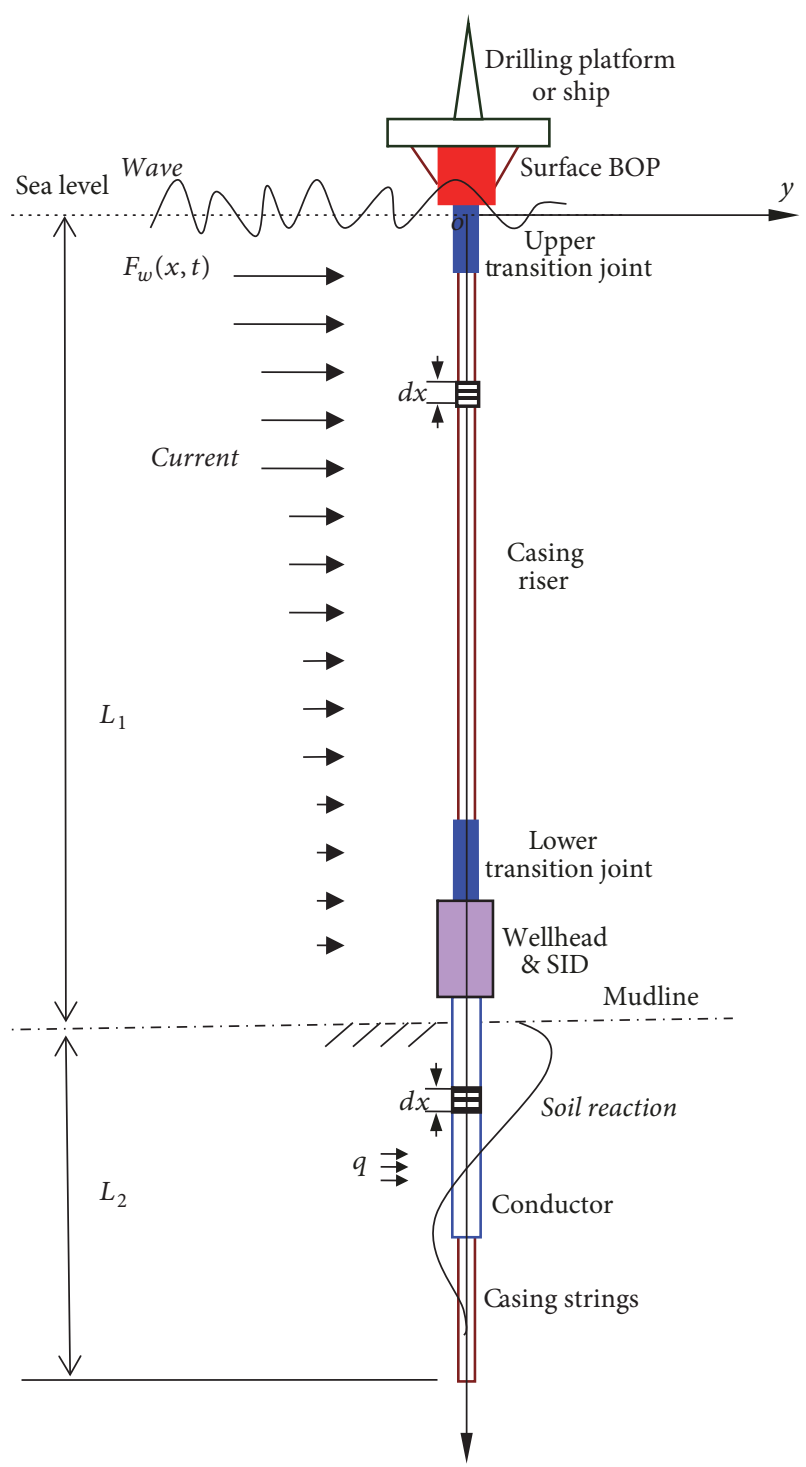

(a)

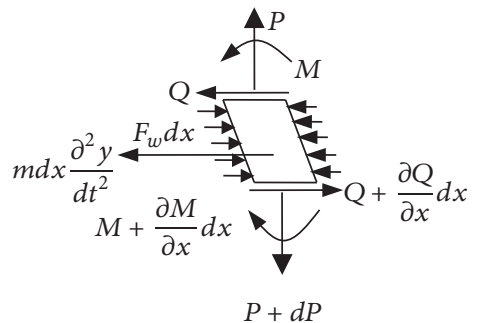

(b)

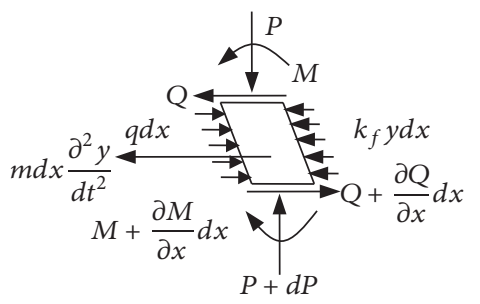

(c)

FIGURE 1: Forces diagram of SBOP system.

The bending stiffness of the riser can be calculated easily; however, the strings under the mudline are much more complicated containing the conductor, cement, and surface casing. Su et al. (2008) described a method to obtain the equivalent bending rigidity [13]; the equivalent bending rigidity of the casing string can be determined by

$$
\begin{aligned}
\left.E I(x)\right|_{x=L_{\mathrm{uj} j} ; x=L_{\mathrm{lj}}} & =\frac{\pi}{64} E_{\mathrm{stl}}\left(D_{\mathrm{rj}}^{4}-d_{\mathrm{rj}}^{4}\right) ; \\
\left.E I(x)\right|_{x=L_{r}} & =\frac{\pi}{64} E_{\mathrm{stl}}\left(D_{r}^{4}-d_{r}^{4}\right) ; \\
\left.E I(x)\right|_{x=L_{\mathrm{sid}}} & =\frac{\pi}{64} E_{\mathrm{stl}}\left(D_{\mathrm{rs}}^{4}-d_{\mathrm{rs}}^{4}\right)
\end{aligned}
$$




$$
\begin{aligned}
\left.E I(x)\right|_{L_{1}<x \leq L_{1}+L_{2}}= & \frac{\pi}{64} E_{\text {stl }}\left[\left(D_{r}^{4}-d_{r}^{4}\right)+\left(D_{s}^{4}-d_{s}^{4}\right)\right] \\
& +\frac{0.6 \pi}{64} E_{\mathrm{ce}}\left(d_{c}^{4}-D_{s}^{4}\right) \\
L_{1}= & L_{\mathrm{uj}}+L_{r}+L_{\mathrm{lj}}+L_{\mathrm{sid}}+L_{\mathrm{ml}} \\
L_{2}= & L_{c}+L_{\mathrm{sc}}
\end{aligned}
$$

where $E_{\text {stl }}$ is the elastic modulus of steel, Pa; $E_{\text {ce }}$ is the elastic modulus of the cement sheath between the conductor and the surface casing, $\mathrm{Pa} ; D_{r}, d_{r}$ are the outer and inside diameters, respectively, of the riser, $\mathrm{m} ; D_{\mathrm{rj}}, d_{\mathrm{rj}}$ are the outer and inside diameters of the transition joint, $\mathrm{m} ; D_{\mathrm{rs}}$ and $d_{\mathrm{rs}}$ are the equivalent outer and inside diameters of the SID, m; $D_{c}, d_{c}$ are the outer and inside diameters of the conductor, $\mathrm{m} ; D_{s}$, $d_{s}$ are the outer and inside diameters of the surface casing string, m; $L_{\mathrm{uj}}, L_{r}, L_{\mathrm{lj}}, L_{\mathrm{sid}}, L_{\mathrm{ml}}$ are the lengths of the upper transition joint, riser, lower transition joint, SID, and the conductor above the mudline, $\mathrm{m}$; and $L_{c}, L_{\mathrm{sc}}$ are the lengths of the conductor under the mudline and surface casing string, respectively, $m$.

The riser mass per unit length should include the mass of the riser itself and the internal drilling mud [8]. The conductor and casing string mass per unit length include the mass of the conductor, the surface casing, and the cement sheath between them. The axial force of the riser-conductor can be obtained as in (3). For the riser, the axial force is its effective tension $[8,13]$, while, in general, the axial force on the SID may be tensile and the force on the conductor and casing string is compressive.

$$
\begin{aligned}
& P_{1}(x)_{\min }=T_{0}-\frac{\pi}{4} \\
& \cdot g\left[\left(\rho_{r} D_{\mathrm{rj}}^{2}-\rho_{r} d_{\mathrm{rj}}^{2}+\rho_{m} d_{\mathrm{rj}}^{2}-\rho_{w} D_{\mathrm{rj}}^{2}\right)\left(L_{\mathrm{uj}}+L_{\mathrm{lj}}\right)\right. \\
& \left.\quad+\left(\rho_{r} D_{r}^{2}-\rho_{r} d_{r}^{2}+\rho_{m} d_{r}^{2}-\rho_{w} D_{r}^{2}\right) L_{r}\right] \\
& P_{2}(x)_{\min }=P_{1}(x)_{\min }-\frac{\pi}{4} \\
& \quad \cdot g\left[\left(\rho_{r} D_{\mathrm{rs}}^{2}-\rho_{r} d_{\mathrm{rs}}^{2}+\rho_{m} d_{\mathrm{rs}}^{2}-\rho_{w} D_{\mathrm{rs}}^{2}\right) L_{\mathrm{sid}}\right. \\
& \quad+\rho_{c}\left(D_{c}^{2}-d_{c}^{2}\right)\left(L_{\mathrm{ml}}+L_{c}\right)+\rho_{s}\left(D_{s}^{2}-d_{s}^{2}\right) L_{\mathrm{sc}} \\
& \left.\quad+\rho_{\mathrm{ce}}\left(d_{c}^{2}-D_{s}^{2}\right) L_{\mathrm{sc}}\right]+F_{f}(x),
\end{aligned}
$$

where $P_{1}$ is the vertical force along the riser, $\mathrm{N} ; P_{2}$ is the vertical force along the SID, conductor, and surface casing string, $\mathrm{N} ; T_{0}$ is the top tension of riser, $\mathrm{N} ; \rho_{r}$ is the riser density, $\mathrm{kg} / \mathrm{m}^{3} ; \rho_{m}$ is the drilling mud density, $\mathrm{kg} / \mathrm{m}^{3} ; \rho_{w}$ is the seawater density, $\mathrm{kg} / \mathrm{m}^{3} ; \rho_{c}$ is the conductor density, $\mathrm{kg} / \mathrm{m}^{3} ; \rho_{s}$ is the surface casing string density, $\mathrm{kg} / \mathrm{m}^{3} ; \rho_{\text {ce }}$ is the cement sheath density, $\mathrm{kg} / \mathrm{m}^{3} ; g$ is the acceleration of gravity, $\mathrm{m} / \mathrm{s}^{2}$; $W_{c}$ is the weight per length of the casing string, N/m; and $F_{f}$ is the outside friction of the conductor and casing string, $\mathrm{N}$.
The stiffness of the conductor and casing string can be derived from $p-y$ curves under period loads according to the actual soil considerations [19]. The damping constant of the conductor and casing string can be expressed with the material damping and the radiation damping (Gazetas and Dobry, 1984) [20].

2.2. Boundary and Initial Conditions. As (1) is a fourthorder equation, four boundary conditions are needed. For the riser, the lateral displacement and bending moment of the upper transition joint are taken as two boundary conditions [21]. For the conductor and casing string, the shear force and the bending moment at their bottom are two lower boundary conditions and can be assumed to be zero. These four boundary conditions can be represented by

$$
\begin{gathered}
y(0, t)=S(t) \\
M(0, t)=\left.E I \frac{\partial^{2} y(x, t)}{\partial x^{2}}\right|_{x=0}=K_{\mathrm{ru}} \theta_{\mathrm{ru}} \\
M\left(L_{1}+L_{2}, t\right)=\left.E I(x) \frac{\partial^{2} y(x, t)}{\partial x^{2}}\right|_{x=L_{1}+L_{2}}=0 . \\
Q\left(L_{1}+L_{2}, t\right)=\left.E I(x) \frac{\partial^{3} y(x, t)}{\partial x^{3}}\right|_{x=L_{1}+L_{2}}=0
\end{gathered}
$$

The initial condition of the equation of motion is

$$
y(x, 0)=y_{\text {static }}(x)
$$

where $M$ is the bending moment, $\mathrm{N} \cdot \mathrm{m}^{2} ; \mathrm{Q}$ is the shear force, $\mathrm{N} ; y_{\text {static }}$ is the lateral displacement of the static riserconductor system, $\mathrm{m} ; K_{\mathrm{ru}}$ is the upper rotational stiffness of the transition joint, $\mathrm{N} \cdot \mathrm{m} / \mathrm{rad}$; and $\theta_{\text {ru }}$ is the upper rotation angle of the transition joint, rad.

$S(t)$ is the horizontal deviation of drilling platform motion from its initial location, and it sums the mean offset and the platform drift responding to random waves (Sexton and Agbezuge, 1976) [22]. It can be expressed as follows:

$$
\begin{aligned}
S(t)= & S_{0}+S_{L} \sin \left(\frac{2 \pi t}{T_{L}}\right) \\
& +\sum_{i=1}^{n} S_{n} \cos \left(k_{n} S(t)-\omega_{n} t+\phi_{n}+a_{n}\right),
\end{aligned}
$$

where $S_{0}$ is the mean offset of the platform, m; $S_{L}$ is the drift amplitude of the platform, $m ; T_{L}$ is the drift period of the platform, s; and $S_{n}, k_{n}, \omega_{n}, \phi_{n}, \alpha_{n}$ are the wave amplitude, wave number, circular frequency, initial phase, and phase difference of the wave $n$, respectively. These parameters can be obtained by wave theory and response curves in $[21,22]$.

2.3. Equation Solution Using FDM. It is difficult to solve the equations analytically; therefore, numerical simulation with the finite difference method was adopted in this paper. 
The riser-conductor string is divided into $n$ equal portions and the length of each section is $h$. By using the threepoint difference format to replace the first- and second-order derivative schemes, the five-point difference format takes place of the fourth-order derivative scheme subsequently in (1). Then the finite differential equations of the riserconductor string can be obtained, which can be shown as follows:

$$
\begin{aligned}
a_{i} y_{i}^{j+1}= & h_{i}-b_{i} y_{i+2}^{j}-c_{i} y_{i+1}^{j}-d_{i} y_{i}^{j}-e_{i} y_{i-1 i-1}^{j}-f_{i} y_{i-2}^{j} \\
& -g_{i} y_{i}^{j-1} \\
a_{i}= & \frac{m_{i}}{\Delta t^{2}}+\frac{c_{s i}}{2 \Delta t} \\
b_{i}= & \frac{(E I)_{i+1}}{\Delta h^{2}} \\
c_{i}= & \frac{-2(E I)_{i+1}-2(E I)_{i}+P_{i}}{\Delta h^{2}} \\
d_{i}= & \frac{(E I)_{i+1}+4(E I)_{i}+(E I)_{i-1}-2 P_{i}}{\Delta h^{2}}-\frac{2 m_{i}}{\Delta t^{2}}+k_{i} \\
e_{i}= & \frac{-2(E I)_{i}-2(E I)_{i-1}+P_{i}}{\Delta h^{2}} \\
f_{i}= & \frac{(E I)_{i-1}}{\Delta h^{2}} \\
g_{i}= & \frac{m_{i}}{\Delta t^{2}}-\frac{c_{s i}}{2 \Delta t} \\
h_{i}= & F_{i}^{j} .
\end{aligned}
$$

According to the difference scheme, the differential equations of the upper boundary condition are expressed as in (8) and the lower boundary condition are shown as in (9):

$$
\begin{aligned}
y_{0}^{j}= & s(j \Delta t) \\
y_{-1}^{j}= & \frac{\left(2-K_{r} \Delta h / E_{1} I_{1}\right)}{\left(-2-K_{r} h / E_{1} I_{1}\right)} y_{1}^{j}+\frac{4}{\left(2+K_{\mathrm{r}} \Delta h / E_{0} I_{0}\right)} y_{0}^{j} \\
y_{N+1}^{j}= & 2 y_{N}^{j}-y_{N-1}^{j} \\
b_{N} y_{N+2}^{j}= & \left(2 b_{N}-N_{N}\right) y_{N+1}^{j}-\left(b_{N}-f_{N}\right) y_{N}^{j} \\
& -\left(2 f_{N}-N_{N}\right) y_{N-1}^{j}+f_{N} y_{N-2}^{j} .
\end{aligned}
$$

When $t=0$, removing the time items in the equations above, the initial conditions can be obtained by the difference equations. The static lateral deformation of the riserconductor system can be easily solved using a matrix or the Glesser method.

$$
y_{i}^{0}=y_{\text {static }}(i) \quad i=-1,0,1, \ldots, N+2 .
$$

Starting from the initial conditions, the responses at a series of discrete time instants can be obtained through direct integration. MATLAB was employed to solve the model by time step. Through iterative calculation, the displacement, offset angle, bending moment, shear force, and soil reaction force at each node and any time were calculated.

\section{Free Vibration Equations and Solution for SBOP Riser-Conductor System}

For the free vibration of the riser-conductor system, (1) reduces to

$$
\begin{gathered}
\frac{\partial^{2}}{\partial x^{2}}\left[E(x) I(x) \frac{\partial^{2} y(x, t)}{\partial x^{2}}\right]+\frac{\partial}{\partial x}\left[P(x) \frac{\partial y(x, t)}{\partial x}\right] \\
+m(x) \frac{\partial^{2} y(x, t)}{\partial t^{2}}+k(x) y(x, t)=0 .
\end{gathered}
$$

Assuming that the system is a uniform beam, (11) reduces to

$$
\begin{aligned}
E(x) & I(x) \frac{\partial^{4} y(x, t)}{\partial x^{4}}+P(x) \frac{\partial^{2} y(x, t)}{\partial x^{2}} \\
+m(x) & \frac{\partial^{2} y(x, t)}{\partial t^{2}}+k(x) y(x, t)=0 .
\end{aligned}
$$

The solution of (12) can be calculated according to the beam theory; then the natural frequency and the corresponding natural mode shape of the riser-conductor system can be expressed as follows:

$$
\begin{aligned}
Y(x)= & A \cosh (\beta x)+B \sinh (\beta x)+C \cos (\gamma x) \\
& +D \sin (\gamma x) \\
\beta= & \left(\frac{P}{2 E I}+\left(\frac{P^{2}}{4 E^{2} I^{2}}+\frac{m \omega^{2}}{E I}-\frac{k_{f}}{E I}\right)^{1 / 2}\right)^{1 / 2}, \\
\gamma= & \left(\frac{-P}{2 E I}+\left(\frac{P^{2}}{4 E^{2} I^{2}}+\frac{m \omega^{2}}{E I}-\frac{k_{f}}{E I}\right)^{1 / 2}\right)^{1 / 2},
\end{aligned}
$$

where $A, B, C$, and $D$ are constants that can be found from the initial conditions; $\omega$ is the natural frequency; and $Y(x)$ is the corresponding natural mode shape of the system.

The riser-conductor of the deepwater SBOP system consists of several sections of different diameters shown in Figure 2; therefore, (11) cannot be directly used to solve the problem. Based on the concept of section division and continuation (Cui et al., 2012) [23], a semianalytical approach for analyzing free vibration of the SBOP riser-conductor with variable cross-section is proposed. However, each section of the conductor system is with constant cross-section and can be treated as a uniform beam. So the natural frequency and the mode shape of each segment can be solved with (13). 


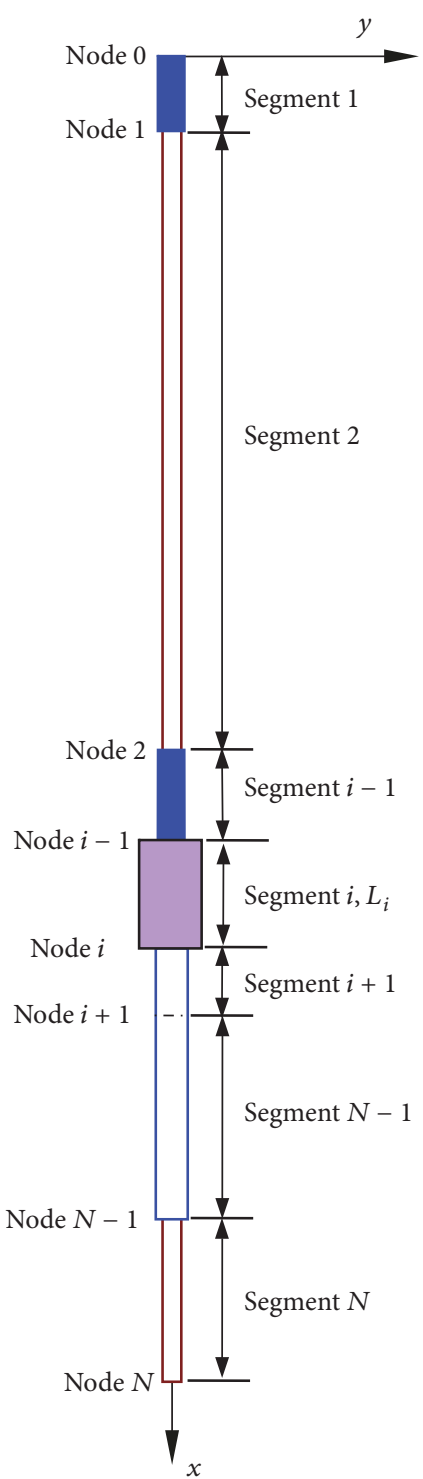

FIgURE 2: The segmental diagram of SBOP riser-conductor.
For the segment $i$, the $i$ th natural mode shape is

$$
\begin{aligned}
Y_{i}(x)= & A_{i} \cosh \left(\beta_{i}\left(x-x_{i-1}\right)\right) \\
& +B_{i} \sinh \left(\beta_{i}\left(x-x_{i-1}\right)\right) \\
& +C_{i} \cos \left(\gamma_{i}\left(x-x_{i-1}\right)\right) \\
& +D_{i} \sin \left(\gamma_{i}\left(x-x_{i-1}\right)\right) .
\end{aligned}
$$

Let $X_{i}(x)=\beta_{i}\left(x-x_{i-1}\right), X X_{i}(x)=\gamma_{i}\left(x-x_{i-1}\right)(i=$ $\left.1,2, N+1 ; x_{0}=0\right)$.

Then (14) becomes

$$
\begin{aligned}
Y_{i}(x)= & A_{i} \cosh \left(X_{i}\right)+B_{i} \sinh \left(X_{i}\right)+C_{i} \cos \left(X X_{i}\right) \\
& +D_{i} \sin \left(X X_{i}\right) .
\end{aligned}
$$

Therefore, the $(i+1)$ th natural mode shape of the segment is expressed as follows:

$$
\begin{aligned}
Y_{i+1}(x)= & A_{i+1} \cosh \left(X_{i+1}\right)+B_{i+1} \sinh \left(X_{i+1}\right) \\
& +C_{i+1} \cos \left(X X_{i+1}\right)+D_{i+1} \sin \left(X X_{i+1}\right) .
\end{aligned}
$$

Since the deflection, slope, moment, and shear force of the $i$ th segment and the $(i+1)$ th segment at node $i$ are equal, assuming $x=x_{i}$,

$$
\begin{aligned}
& Y_{i+1}\left(x_{i}\right)=Y_{i}\left(x_{i}\right) \\
& Y_{i+1}^{\prime}\left(x_{i}\right)=Y_{i}^{\prime}\left(x_{i}\right) \\
& (E I)_{i+1} Y_{i+1}^{\prime \prime}\left(x_{i}\right)=(E I)_{i} Y_{i}^{\prime \prime}\left(x_{i}\right) \\
& (E I)_{i+1} Y_{i+1}^{\prime \prime \prime}\left(x_{i}\right)-P_{i+1} Y_{i+1}^{\prime}\left(x_{i}\right) \\
& \quad=(E I)_{i} Y_{i}^{\prime \prime \prime}\left(x_{i}\right)-P_{i} Y_{i}^{\prime}\left(x_{i}\right) .
\end{aligned}
$$

By substituting (15) and (16) into (17), the following is obtained:

$$
\left[\begin{array}{c}
A_{i+1} \\
B_{i+1} \\
C_{i+1} \\
D_{i+1}
\end{array}\right]=\left[\begin{array}{cccc}
n_{4} m_{1} & n_{3} m_{1} & -n_{2} m_{2} & -n_{1} m_{2} \\
\frac{\beta_{i}}{\beta_{i+1}} n_{3}\left(m_{1}+v_{1}\right) & \frac{\beta_{i}}{\beta_{i+1}} n_{4}\left(m_{1}+v_{1}\right) & \frac{\gamma_{i}}{\beta_{i+1}} n_{1}\left(m_{2}+v_{2}\right) & \frac{-\gamma_{i}}{\beta_{i+1}} n_{2}\left(m_{2}+v_{2}\right) \\
-n_{4} m_{3} & -n_{3} m_{3} & n_{2} m_{4} & n_{1} m_{4} \\
\frac{-\beta_{i}}{\gamma_{i+1}} n_{3}\left(m_{3}+v_{1}\right) & \frac{-\beta_{i}}{\gamma_{i+1}} n_{4}\left(m_{3}+v_{1}\right) & \frac{-\gamma_{i}}{\gamma_{i+1}} n_{1}\left(m_{4}+v_{2}\right) & \frac{\gamma_{i}}{\gamma_{i+1}} n_{2}\left(m_{4}+v_{2}\right)
\end{array}\right]\left[\begin{array}{c}
A_{i} \\
B_{i} \\
C_{i} \\
D_{i}
\end{array}\right],
$$

where

$$
\begin{aligned}
& n_{4}=\cosh \left(\beta_{i} l_{i}\right) \\
& m_{1}=\frac{(E I)_{i} \beta_{i}^{2}+(E I)_{i+1} \gamma_{i+1}^{2}}{(E I)_{i+1}\left(\beta_{i+1}^{2}+\gamma_{i+1}^{2}\right)} \\
& m_{2}=\frac{(E I)_{i} \gamma_{i}^{2}-(E I)_{i+1} \gamma_{i+1}^{2}}{(E I)_{i+1}\left(\beta_{i+1}^{2}+\gamma_{i+1}^{2}\right)}
\end{aligned}
$$$$
n_{2}=\cos \left(\gamma_{i} l_{i}\right)
$$$$
n_{3}=\sinh \left(\beta_{i} l_{i}\right) \text {, }
$$ 

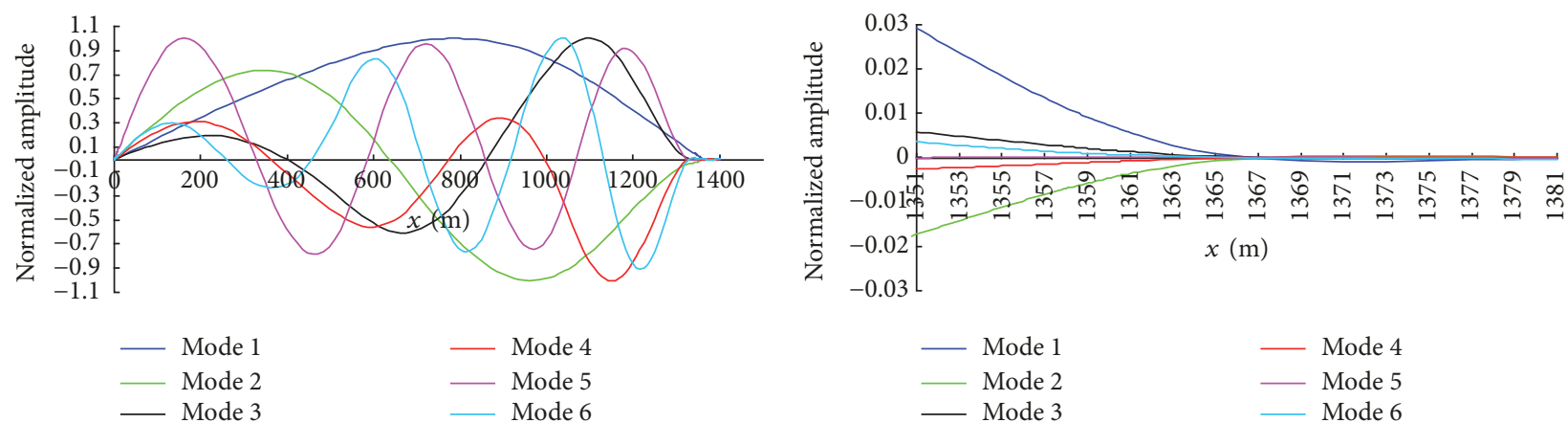

- Mode 4

Mode 2

- Mode 5

FIGURE 3: First five natural mode shapes for SBOP riser-conductor.
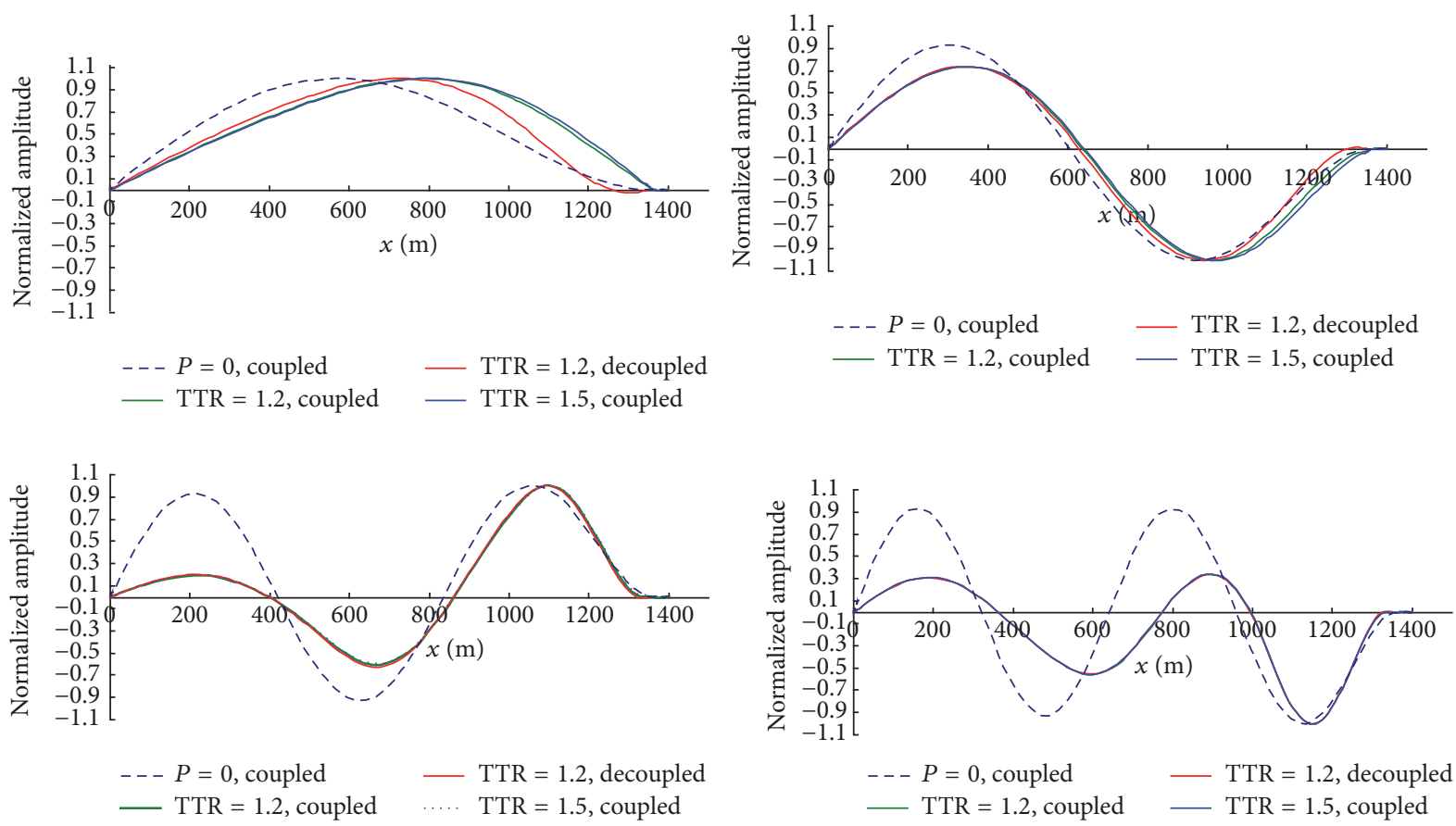

FIGURE 4: First four natural mode shapes for 4 situations.
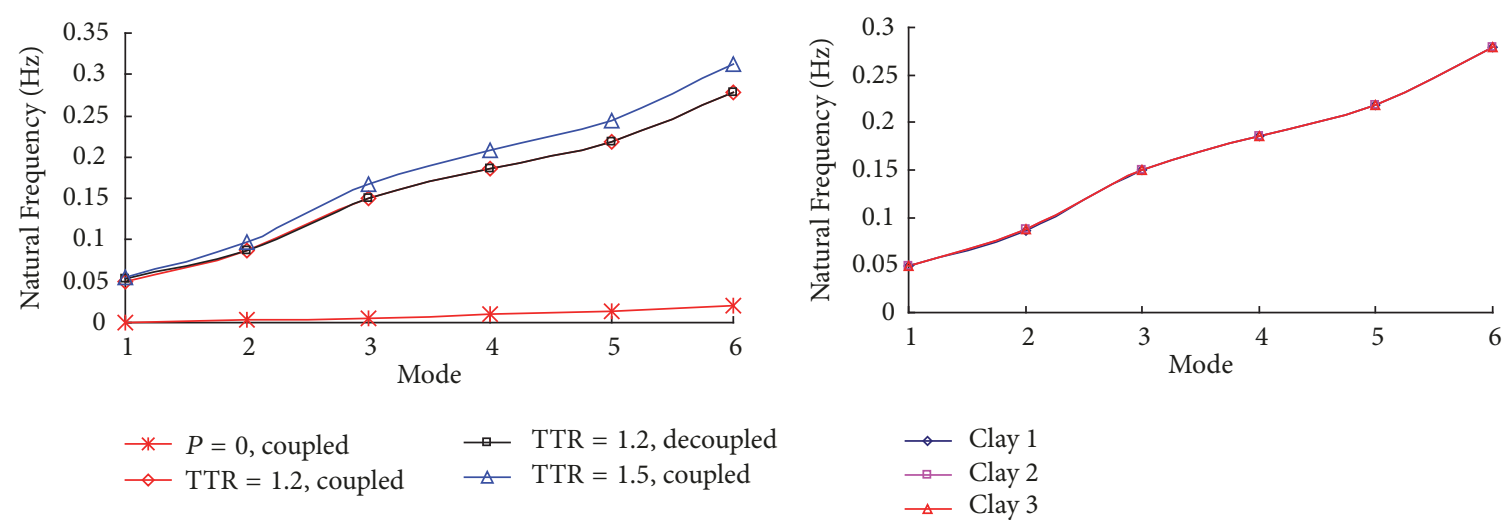

FIGURE 5: Mode shapes and natural frequency with variable TTR and soil type. 


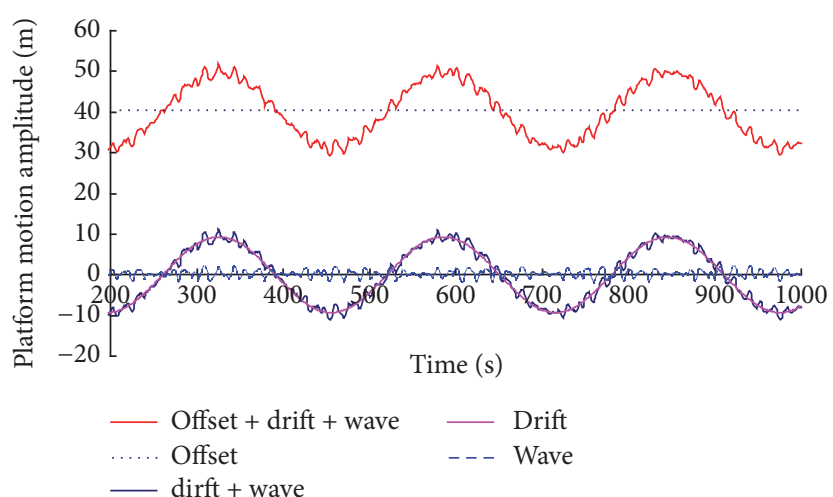

FIGURE 6: Dynamic response of the platform.

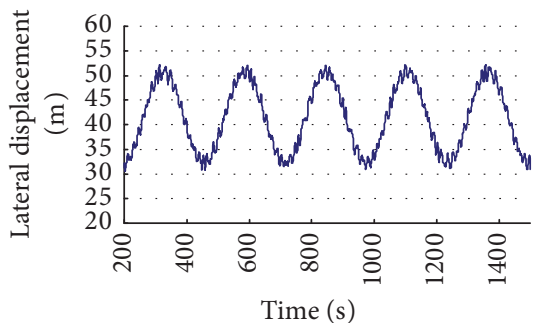

— Bottom of USJ

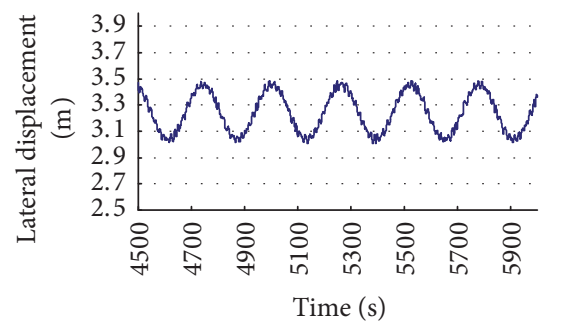

_ Top of LSJ

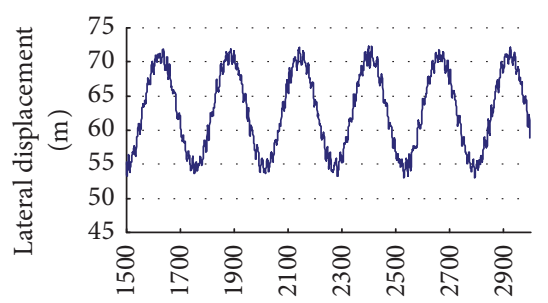

Time (s)

- Riser $(-300 \mathrm{~m})$

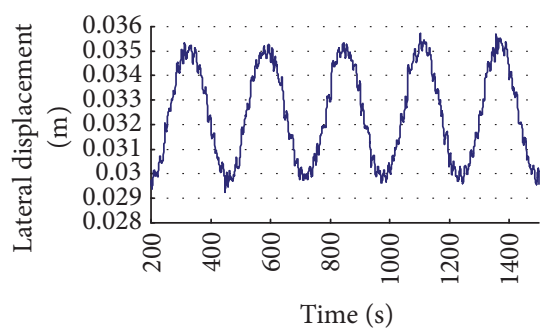

_ Wellhead

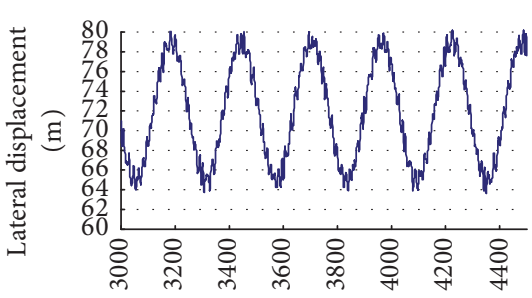

Time (s)

- Riser $(-600 \mathrm{~m})$

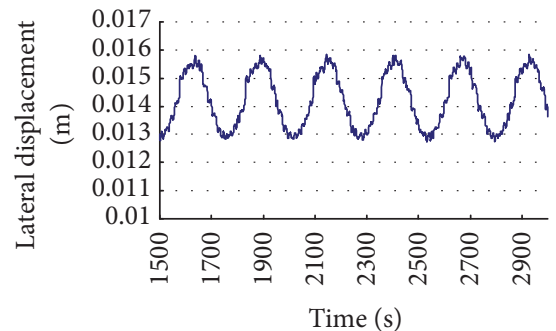

— Mudline

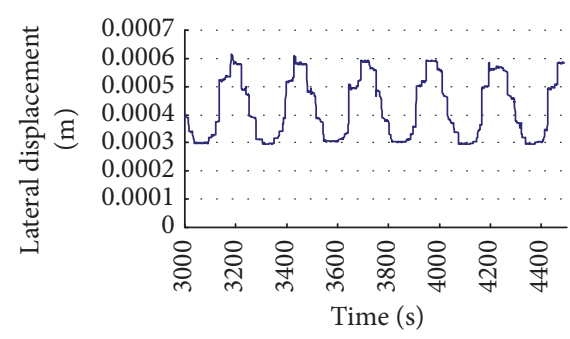

— Under mudline $-5 \mathrm{~m}$

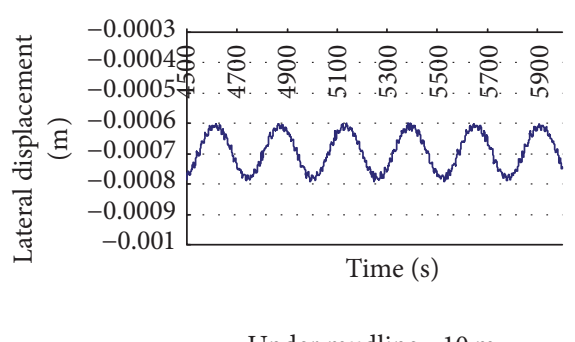

- Under mudline $-10 \mathrm{~m}$

Figure 7: Lateral displacement at different positions.

$$
\begin{aligned}
& m_{3}=\frac{(E I)_{i} \beta_{i}^{2}-(E I)_{i+1} \beta_{i+1}^{2}}{(E I)_{i+1}\left(\beta_{i+1}^{2}+\gamma_{i+1}^{2}\right)}, \\
& m_{4}=\frac{(E I)_{i} \gamma_{i}^{2}+(E I)_{i+1} \beta_{i+1}^{2}}{(E I)_{i+1}\left(\beta_{i+1}^{2}+\gamma_{i+1}^{2}\right)}
\end{aligned}
$$$$
v_{1}=\frac{P_{i+1}-P_{i}}{(E I)_{i+1}\left(\beta_{i+1}^{2}+\gamma_{i+1}^{2}\right)},
$$$$
v_{2}=\frac{P_{i}-P_{i+1}}{(E I)_{i+1}\left(\beta_{i+1}^{2}+\gamma_{i+1}^{2}\right)} \text {. }
$$ 


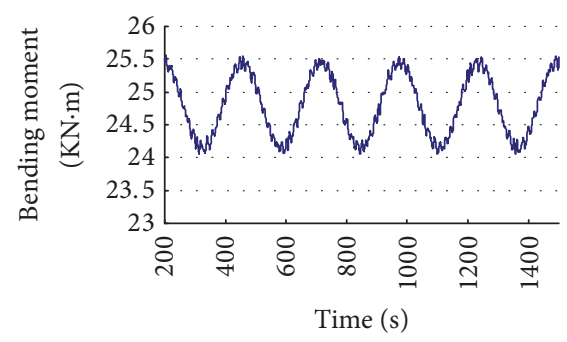

— Bottom of USJ

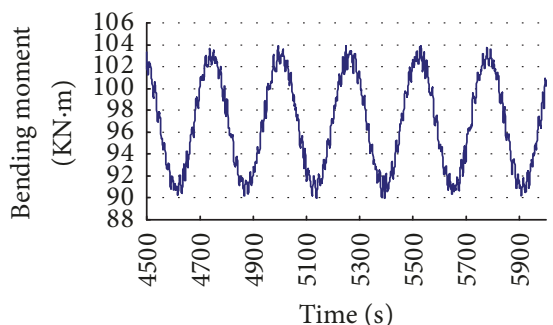

— Top of LSJ
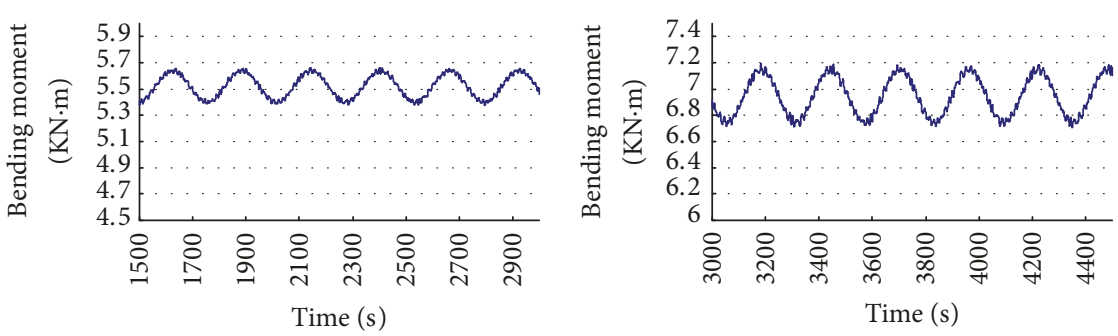

Riser $(-300 \mathrm{~m})$

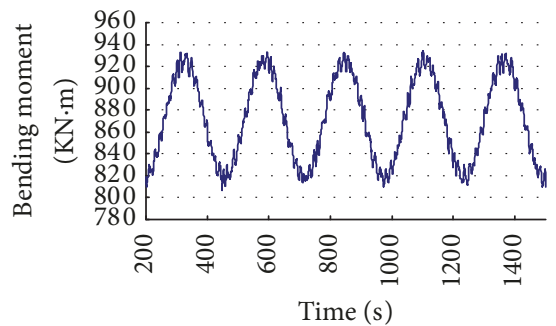

— Wellhead

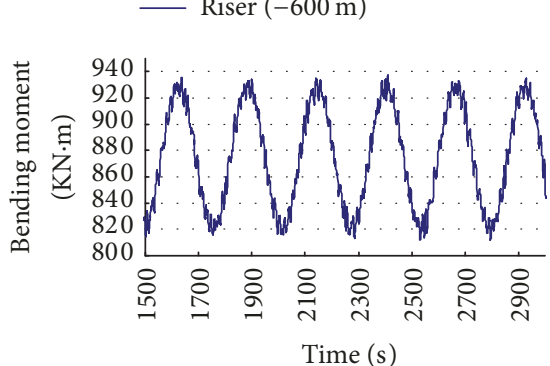

— Mudline

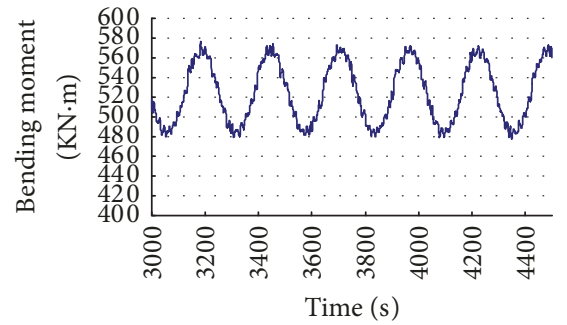

_ Under mudline $-5 \mathrm{~m}$

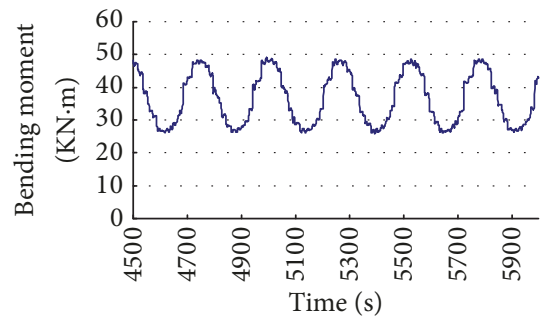

_ Under mudline $-10 \mathrm{~m}$

Figure 8: Dynamic bending moment on the riser, wellhead, and conductor.

Let

$$
\begin{aligned}
A_{(i+1)}= & {\left[\begin{array}{llll}
A_{i+1} & B_{i+1} & C_{i+1} & D_{i+1}
\end{array}\right]^{T}, } \\
A_{(i)}= & {\left[\begin{array}{llll}
A_{i} & B_{i} & C_{i} & D_{i}
\end{array}\right]^{T}, } \\
Z_{(i)}= & {\left[\begin{array}{cccc}
n_{4} m_{1} & n_{3} m_{1} & -n_{2} m_{2} & -n_{1} m_{2} \\
\frac{\beta_{i}}{\beta_{i+1}} n_{3}\left(m_{1}+v_{1}\right) & \frac{\beta_{i}}{\beta_{i+1}} n_{4}\left(m_{1}+v_{1}\right) & \frac{\gamma_{i}}{\beta_{i+1}} n_{1}\left(m_{2}+v_{2}\right) & \frac{-\gamma_{i}}{\beta_{i+1}} n_{2}\left(m_{2}+v_{2}\right) \\
-n_{4} m_{3} & -n_{3} m_{3} & n_{2} m_{4} & n_{1} m_{4} \\
\frac{-\beta_{i}}{\gamma_{i+1}} n_{3}\left(m_{3}+v_{1}\right) & \frac{-\beta_{i}}{\gamma_{i+1}} n_{4}\left(m_{3}+v_{1}\right) & \frac{-\gamma_{i}}{\gamma_{i+1}} n_{1}\left(m_{4}+v_{2}\right) & \frac{\gamma_{i}}{\gamma_{i+1}} n_{2}\left(m_{4}+v_{2}\right)
\end{array}\right] . }
\end{aligned}
$$

Then (18) becomes

$$
A_{(i+1)}=Z_{(i)} A_{(i)} .
$$

From (21),

$$
A_{(N)}=Z A_{(1)} \text {, }
$$

where

$$
Z=Z_{(N-1)} Z_{(N-2)} \cdots Z_{(2)} Z_{(1)} .
$$

As (23) is the function of the natural frequency $\omega$ of the riser-conductor, the relationship of the undetermined 

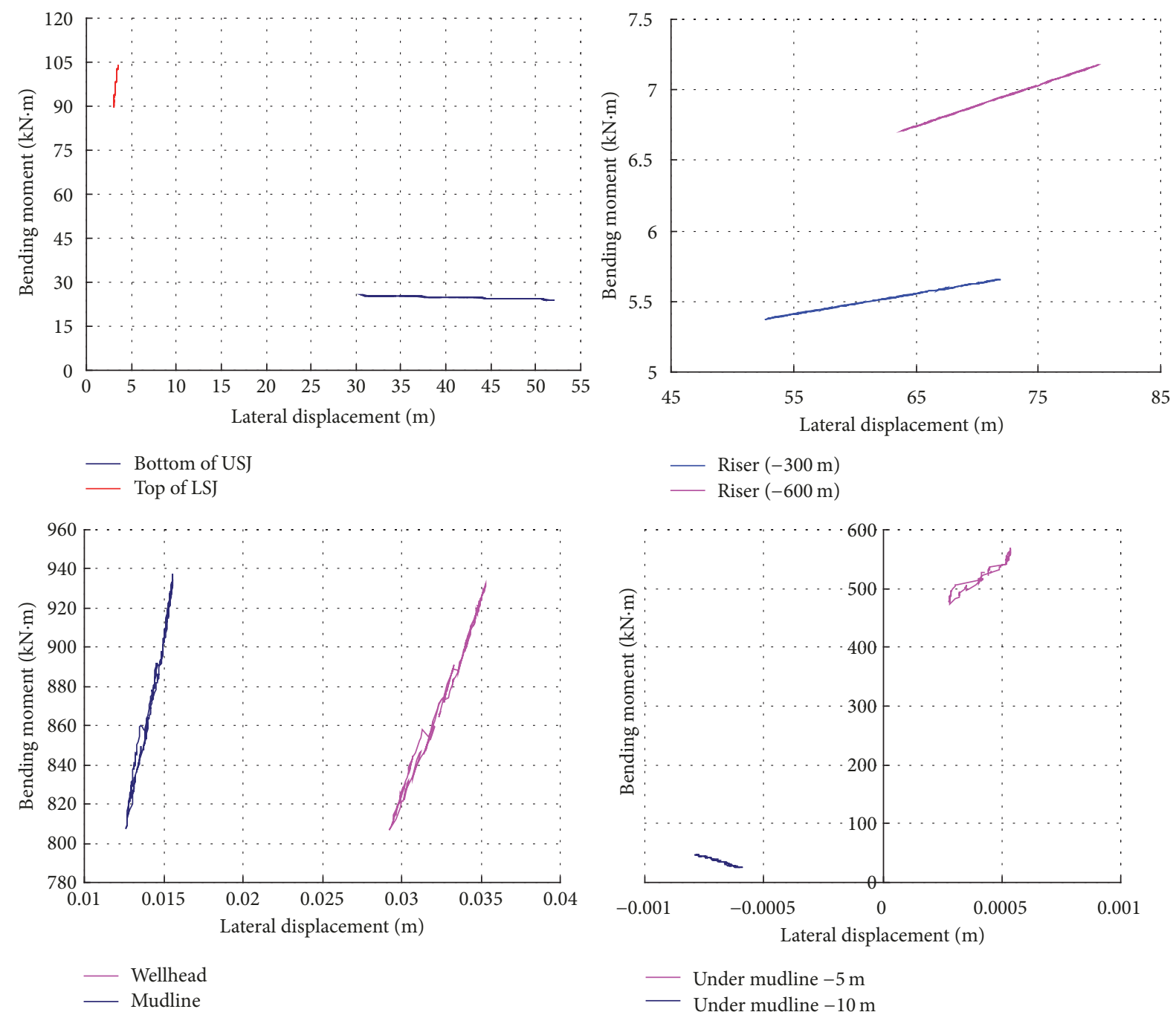

FIGURE 9: Moment-displacement curves.

coefficient between the $N$ th segment and the 1st segment is established.
Assuming $S(0)=0$, follows (4); from the boundary conditions, we get (24):

$$
\begin{aligned}
& A_{1}=C_{1}=0
\end{aligned}
$$

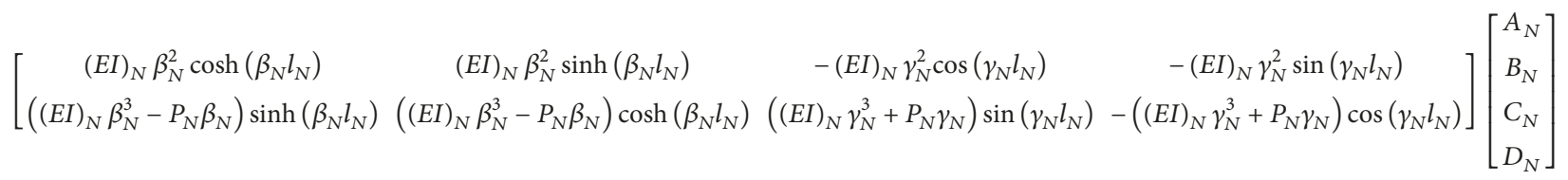

$$
\begin{aligned}
& =0 \text {. }
\end{aligned}
$$

Solving (24) using the secant iteration method by MAT$\mathrm{LAB}$ to obtain the natural frequencies $\omega_{\mathrm{i}}, i=1,2, \ldots$, the iteration formation is shown as in

$$
\omega_{k+1}=\omega_{k}-f\left(\omega_{k}\right) \frac{\omega_{k}-\omega_{k-1}}{f\left(\omega_{k}\right)-f\left(\omega_{k-1}\right)} .
$$

Then, (22) is used to get the constants $A_{(i)}, i=1,2, \ldots, N$, and the corresponding natural mode shapes of the riserconductor.

\section{Case Study and Discussion}

A case study with the parameters given in Table 1 is carried out.

Seabed soil conditions vary substantially around the world. However, to simplify the calculation process and compare the results, the soil type below the mudline $0-60 \mathrm{~m}$ is assumed as all clay or sand layer. The six soil type properties are listed in Table 2. 
TABLE 1: Basic parameters.

\begin{tabular}{|c|c|}
\hline Parameters & Value \\
\hline Water depth/m & 1361.0 \\
\hline Length of casing riser/m & 1350.0 \\
\hline $\mathrm{OD}$ of casing riser $/ \mathrm{m}$ & 0.3397 \\
\hline ID of casing riser/m & 0.3112 \\
\hline Platform offset/\% water depth & 3.0 \\
\hline Tension ratio of riser (TTR) & 1.2 \\
\hline Velocity of surface wind $/ \mathrm{m} \cdot \mathrm{s}^{-1}$ & 1.0 \\
\hline Tide velocity $/ \mathrm{m} \cdot \mathrm{s}^{-1}$ & 0.5 \\
\hline Current velocity $/ \mathrm{m} \cdot \mathrm{s}^{-1}$ & 1.0 \\
\hline Significant wave height/m & 12 \\
\hline Significant wave period/s & 8 \\
\hline Platform slow drift amplitude/m & 9.3 \\
\hline Platform slow drift period/s & 259.8 \\
\hline Elastic modulus of steel/GPa & 210.0 \\
\hline Density of steel $/ \mathrm{kg} \cdot \mathrm{m}^{-3}$ & 7850.0 \\
\hline Density of seawater $/ \mathrm{kg} \cdot \mathrm{m}^{-3}$ & 1030.0 \\
\hline Density of drilling mud $/ \mathrm{kg} \cdot \mathrm{m}^{-3}$ & 1200.0 \\
\hline Wellhead above the mudline/m & 3.0 \\
\hline Height of SID/m & 8.0 \\
\hline Equivalent outer diameter of SID/m & 0.8 \\
\hline Length of transition joint/m & 10.0 \\
\hline Equivalent $\mathrm{OD}$ of transition joint $/ \mathrm{m}$ & 0.3683 \\
\hline Equivalent WT of transition joint/m & 0.0508 \\
\hline Length of conductor/m & 60.0 \\
\hline OD of conductor $/ \mathrm{mm}$ & 0.762 \\
\hline WT of conductor $/ \mathrm{mm}$ & 0.0254 \\
\hline Elastic modulus of cement sheath/GPa & 18.0 \\
\hline Length of surface casing/m & 500.0 \\
\hline
\end{tabular}

4.1. Natural Frequencies and Mode Shapes of the SBOP RiserConductor System. The natural frequencies with the data given in Tables 1 and 2 with the proposed method are listed in Table 3. And Figure 3 shows the first six mode shapes of the riser-conductor of the SBOP drilling system. As seen especially in Figure 3, the amplitudes of the mode shapes on the SID, wellhead, and conductor are very small because the soil reaction causes stiffness in these sections.

The mode shape comparison results for 4 situations $(P=$ 0 , coupled; TTR $=1.2$, coupled; TTR $=1.5$, coupled; TTR $=$ 1.2, decoupled) are shown in Figure 4. From these figures, it can be observed that the mode shapes have some difference between the coupled and decoupled method; however, there is no obvious difference when the mode number is greater than 3. In addition, axial force has great effect on the mode shape and natural frequency, because axial force directly affects the stiffness of bending.

Although the TTR has little effect on the mode shape, its effect on the natural frequencies for the modes is obvious as shown in Figure 5. It can be seen that with the increase of TTR the natural frequency of the riser-conductor increases as well. However, it would not have an effect on the natural frequency much for the SBOP riser-conductor. It was also observed that the soil types surrounding the conductor under the mudline have very tiny effect on the natural frequency for the riserconductor for SBOP drilling system.

4.2. The Dynamic Response of the SBOP Riser-Conductor. To analyze the dynamic response of the riser-conductor for the SBOP drilling system, lateral displacement, bending moment, and soil reactions at the different positions of the riserconductor string are compared. Given that some papers have discussed the response of the SBOP riser, this work focuses on the comparison of the dynamic responses on the wellhead and the conductor with variable conditions.

4.2.1. Dynamic Response of the Platform. The P-M spectrum has been employed to calculate the motion of the platform and the simulation results are shown in Figure 6. From this figure, the motion amplitude of the platform is relatively small without considering offset and drift. This motion considering more conditions will obviously cause the riser response.

4.2.2. Lateral Displacement at Different Positions of the RiserConductor String. For the SBOP drilling system, some key joint points are critical to the drilling operation. This work focuses on 4 positions on the riser, namely, the bottom of the upper transition joint (USJ), the elevation $300 \mathrm{~m}$ under the mean water level (MWL), the elevation $800 \mathrm{~m}$ under the mean water level (MWL), and the top of the lower transition (stress) joint (LSJ), and 4 positions on the conductor, including the subsea wellhead $(\mathrm{WH})$, the mudline (ML), $-5 \mathrm{~m}$ under the ML, and $-10 \mathrm{~m}$ under the ML.

The first four pictures in Figure 7 show the lateral displacements at different locations on the riser and the last four pictures show the displacements on the wellhead or the conductor. The lateral displacement amplitude at the elevation of $800 \mathrm{~m}$ of the riser under the MWL is the highest in the first four pictures; the displacement amplitude at the wellhead is more than other places on the conductor under the ML. Their periods are the same in the time domain, following the platform motion.

4.2.3. Dynamic Bending Moment on the Riser, the Wellhead, and the Conductor. In Figure 8, the bending moment's variations at different positions on the riser, the wellhead, and the conductor are presented. The largest bending moment of the riser focuses on the LSJ, and the moment becomes smaller at the place of the conductor under the $\mathrm{ML}-5 \mathrm{~m}$.

4.2.4. Moment-Displacement Curves. Comparing the bending moment and the lateral displacement in the same position simultaneously in Figure 9, the change of displacement is found to have a certain delay, compared with the bending moment on the conductor, and there is no delay on the riser. The reason is that the nonlinear soil reaction acted on the conductor under the mudline.

It is also found that the displacement varies more at the bottom of the USJ than at the top of the LSJ. The displacement-moment curves change on the negative $x$-axis under the mudline $-10 \mathrm{~m}$, because the displacement of the 
TABLE 2: Soil parameters.

\begin{tabular}{lccccccc}
\hline & Clay 1 & Clay 2 & Clay 3 & & Sand 1 & Sand 2 & Sand 3 \\
\hline Undrained shear strength $/ \mathrm{kPa}$ & 20.0 & 60.0 & 60.0 & Angle of internal friction/degree & 30.0 & 39.5 & 39.5 \\
Submerged unit weight $/\left(\mathrm{kN} / \mathrm{m}^{3}\right)$ & 7.0 & 7.0 & 8.0 & Submerged unit weight $/\left(\mathrm{kN} / \mathrm{m}^{3}\right)$ & 8.5 & 8.5 & 10.0 \\
\hline
\end{tabular}

TABLE 3: First six-order natural frequencies.

\begin{tabular}{lcccccc}
\hline & Mode \#1 & Mode \#2 & Mode \#3 & Mode \#4 & Mode \#5 & Mode \#6 \\
\hline Natural frequencies $/ \mathrm{Hz}$ & 0.04895 & 0.08687 & 0.14998 & 0.18547 & 0.21846 & 0.27866 \\
\hline
\end{tabular}
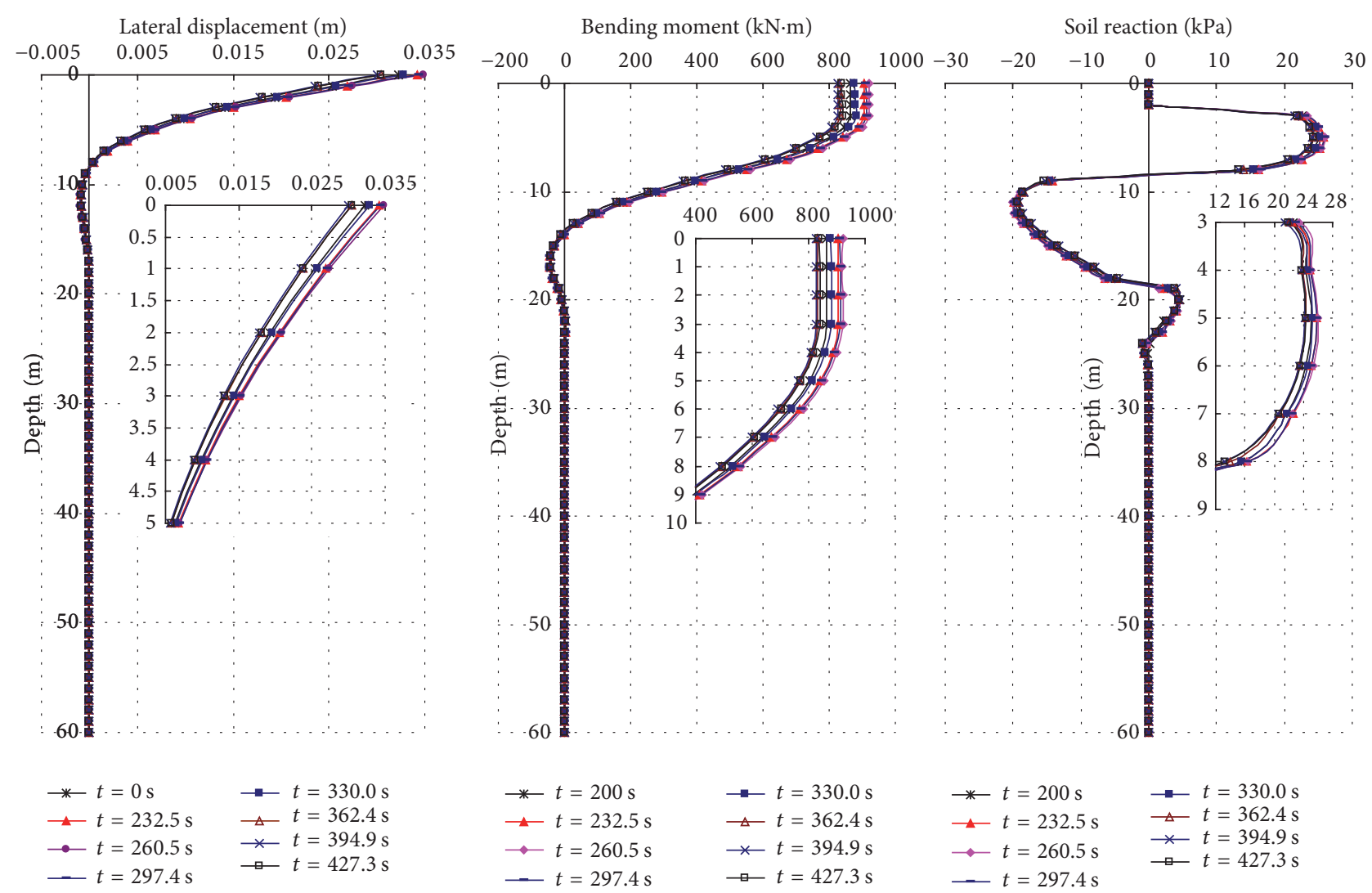

FIgURE 10: Deformation and stresses of the conductor in a drift period.

conductor under a certain depth will be negative or equal zero.

4.2.5. Deformation and Stresses of the Conductor in a Drift Period. The deformation and stress of the casing string below the mudline and the soil reaction force around the casing string are analyzed in a slow-drift period of a drilling platform. When the vibration reaches the steady state, 8 time points $(t=200 \mathrm{~s}, 232.5 \mathrm{~s}, 260.5 \mathrm{~s}, 297.4 \mathrm{~s}, 330.0 \mathrm{~s}, 362.4 \mathrm{~s}$, $394.9 \mathrm{~s}$, and $427.3 \mathrm{~s}$ ) are taken in one period. The lateral displacement, bending moment, and soil reaction along the conductor are shown in Figure 10.

It can be seen from Figure 10 that the deformation, stress, and surrounding soil reaction of the casing string change with time in the slow-drift period. In a period, the maximum lateral displacement is along the column; the relative changes in bending moment and maximum soil reaction are $7.7 \%$, $6.6 \%$, and $3.2 \%$, respectively.

\subsubsection{Sensitivity Analysis of Parameter Changes to Wellhead and Conductor}

vspace10pt(1) Platform Offset and Conductor Size. The different platform offsets of $0 \%, 1 \%, 2 \%, 3 \%, 4 \%, 5 \%, 6 \%$, $7 \%$, and $8 \%$ water depth and different conductor sizes (OD $=762.0 \mathrm{~mm}, 660.4 \mathrm{~mm}$, and $508.0 \mathrm{~mm}$, no conductor) are chosen to compare the results, as shown in Figure 11. The displacement and the bending moment are raised with the offset increase and those have a rapid increase in the condition when there is no conductor. 

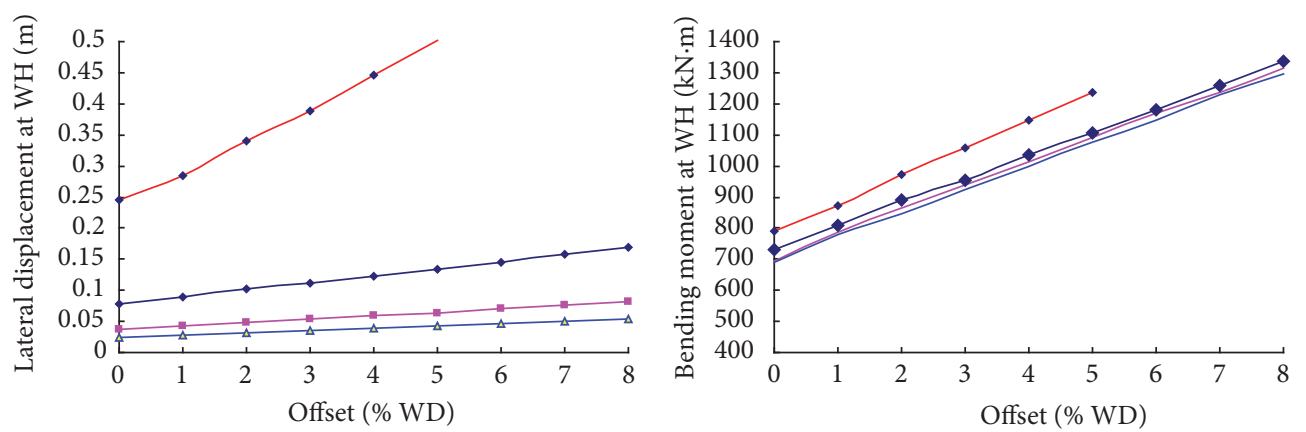

$\rightarrow-$ No conductor $(@ W H)$
$\rightarrow-O D=508.0 \mathrm{~mm}(@ W H)$
$\rightarrow \mathrm{OD}=660.4 \mathrm{~mm}(@ \mathrm{WH})$
$\rightarrow-\mathrm{OD}=762.0 \mathrm{~mm}(@ \mathrm{WH})$

$\rightarrow$ No conductor (@WH)

$\rightarrow$ OD $=508.0 \mathrm{~mm}(@ \mathrm{WH})$

OD = 660.4 mm (@WH)

- OD = 762.0 mm (@WH)
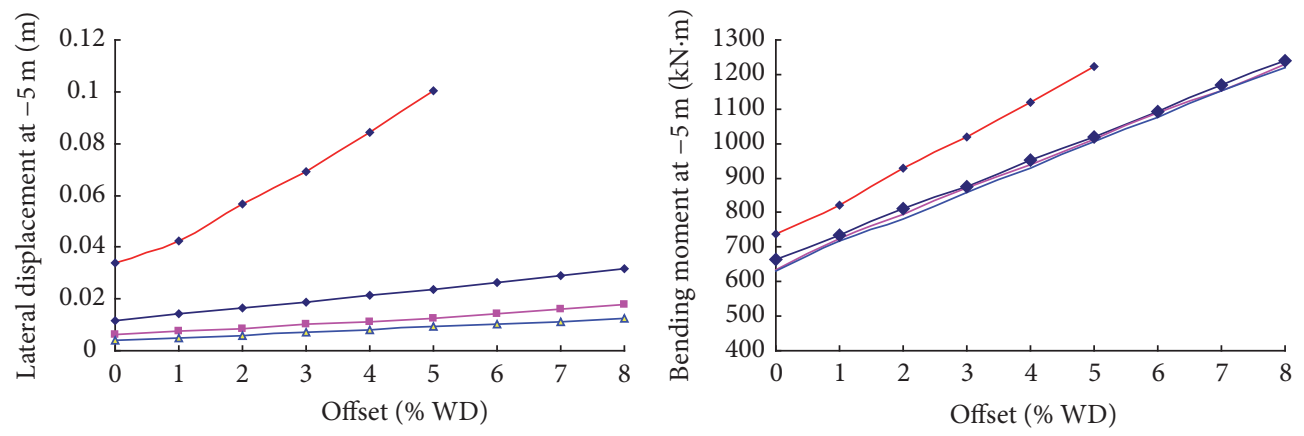

- No conductor (@-2 m)

$\rightarrow \mathrm{OD}=508.0 \mathrm{~mm}(@-2 \mathrm{~m})$

$\rightarrow-\mathrm{OD}=660.4 \mathrm{~mm}(@-2 \mathrm{~m})$

$\rightarrow-\mathrm{OD}=762.0 \mathrm{~mm}(@-2 \mathrm{~m})$

$$
\begin{aligned}
& \longrightarrow \text { No conductor }(@-2 \mathrm{~m}) \\
& \rightarrow-\mathrm{OD}=508.0 \mathrm{~mm}(@-2 \mathrm{~m}) \\
& -\mathrm{OD}=660.4 \mathrm{~mm}(@-2 \mathrm{~m}) \\
& -\mathrm{OD}=762.0 \mathrm{~mm}(@-2 \mathrm{~m})
\end{aligned}
$$

FIGURE 11: Effect of the platform offset and conductor size on wellhead and conductor.
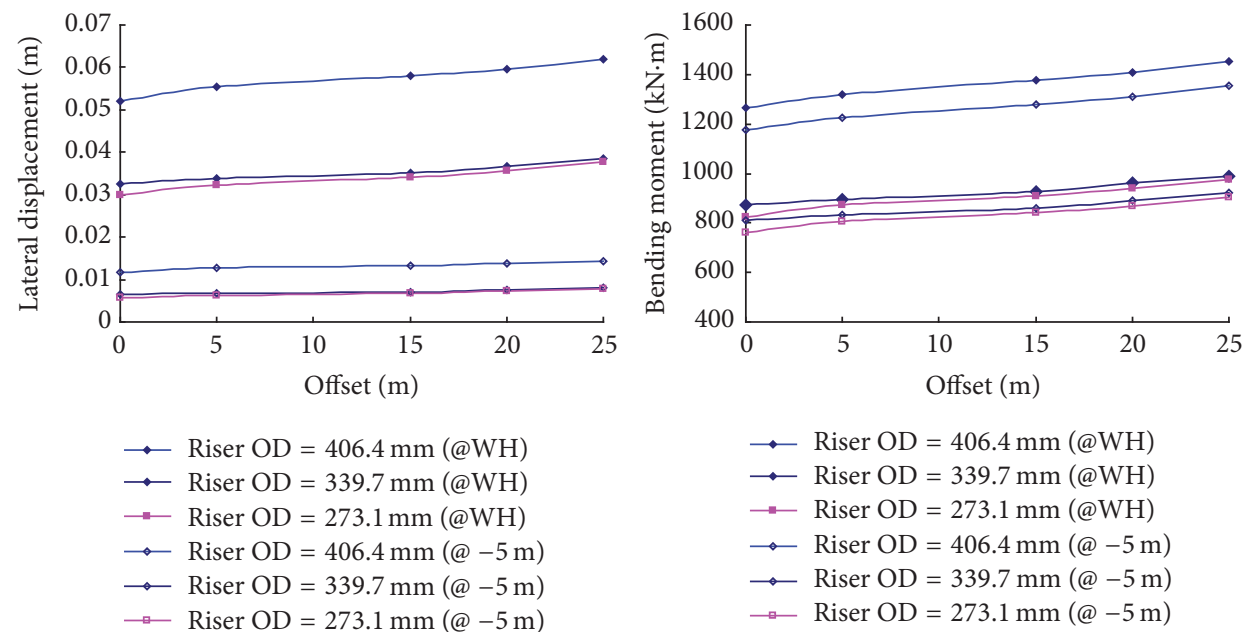

$\longrightarrow$ Riser OD = 406.4 mm (@WH)

$\longrightarrow$ Riser OD = $339.7 \mathrm{~mm}(@ \mathrm{WH})$

$\longrightarrow$ Riser OD = 273.1 mm (@WH)

$\rightarrow$ Riser OD = 406.4 mm $(@-5 \mathrm{~m})$

$\multimap$ Riser OD = $339.7 \mathrm{~mm}(@-5 \mathrm{~m})$

$\rightarrow$ Riser OD = 273.1 mm $(@-5 \mathrm{~m})$

FIGURE 12: Effect of the platform surge amplitude and riser size on wellhead and conductor.

(2) Platform Surge Amplitude and Riser Size. Figure 12 displays the sensitivity of the lateral displacement and the bending moment to the variable surge amplitudes of platform and the riser's outer diameters. In Figure 12, the lateral displacement and the bending moment of the wellhead increase with the greater surge amplitude. The $406.4 \mathrm{~mm}$ diameter riser will 

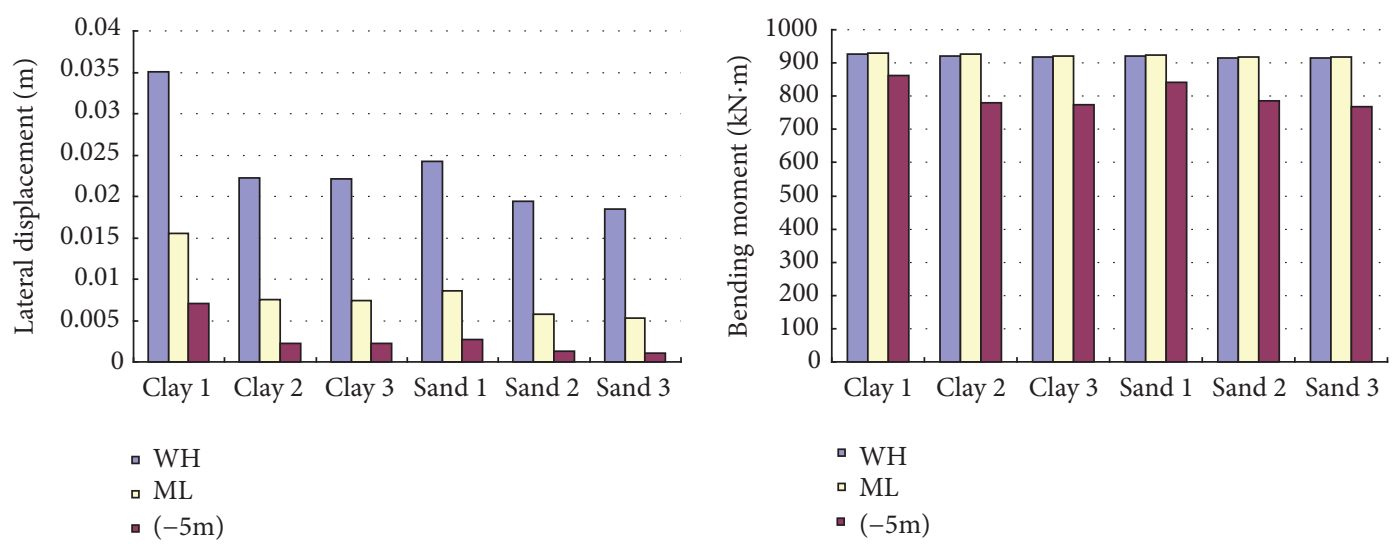

Figure 13: Effect of the soil properties at wellhead, mudline, and $-5 \mathrm{~m}$ on conductor.

transfer more force to the wellhead and the conductor, so the $339.7 \mathrm{~mm}$ diameter riser is the best for the SBOP drilling system.

(3) Soil Properties. As the seabed soil supports the conductor, the soil property is very critical for the transverse stress and deformation of the conductor and the wellhead. Figure 13 compares the displacement and the bending moment of the wellhead and the position of the conductor at the mudline and $5 \mathrm{~m}$ below the mudline, using 6 soil types (see Table 2). The parameter of undrained shear strength (USS) is more sensitive to clay than the submerged unit weight. A lower USS of clay will cause weak conductor support. The parameter of the angle of internal friction is also more sensitive to sand than the submerged unit weight. Also, the bending moment does not change more than the lateral displacement of the wellhead and the conductor.

\section{Conclusion}

For the SBOP drilling system, the riser-conductor is considered as combination sections with different cross-sections subjected to loads throughout its length, and a FDM solution is derived in time domain. Results show that the displacement amplitude at the wellhead is more than in other places of the conductor under mudline. The largest bending moment of the riser focuses on the LSJ, and the moment becomes smaller at the place of the conductor under the $\mathrm{ML}-5 \mathrm{~m}$. The deformation, stress, and surrounding soil reaction of the casing string change with time in the slow-drift period.

Based on the concept of section division and continuation, a semianalytical approach for analyzing free vibration of the SBOP riser-conductor with variable cross-section is proposed, which can actually be applied to any variable cross-section. And this method established for SBOP system natural frequency analysis is reasonable. Results show that the mode shapes have some difference between the coupled and decoupled method. The natural frequencies at diverse modes have little variation with variable TTR. The soil types surrounding the conductor under mudline have very tiny effect on the natural frequency of the riser-conductor system.

\section{Conflicts of Interest}

The authors declare that there are no conflicts of interest regarding the publication of this article.

\section{Acknowledgments}

This work was done at the Drilling Technology Laboratory (DTL) at the Memorial University of Newfoundland, Canada. This work was supported by the National Natural Science Foundation of China (Grant no. 51004119), the Chongqing Research Program of Basic Research and Frontier Technology (Grant no. CSTC2015jcyjA90021), and the Academician Led Special Project of Chongqing Science and Technology Commission (Grant no. cstc2017zdcy-yszxX0009).

\section{References}

[1] P. Azancot, E. Magne, and J. Zhang, Surface BOP_Management System Design Guidelines. Society of Petroleum Engineers, 2002.

[2] "Guidelines for Surface BOP Drilling from Floating MODUs," in Proceedings of the International Association of Drilling Contractors (IADC), 2015.

[3] J. R. Kozicz, "Surface BOP-Recent Experience and Future Opportunities," in Proceedings of Society of Petroleum Engineers, Mumbai, India, 2006.

[4] G. Brander, E. Magne, and T. Newman, "Surface BOP technology steps into deeper water with DP vessels," Oil Gas Journal, vol. 102, no. 17, p. 65, 2004.

[5] A. Simondin, D. MacPherson, N. Touboul, and G. Ragnes, "A deepwater well construction alternative: surface BOP drilling concept using environmental safe guard," in Proceedings of the IADC/SPE Drilling Conference, pp. 153-160, Society of Petroleum Engineers, TX, USA, March 2004.

[6] B. Tarr, T. Taklo, L. A. Olijnik et al., "Surface BOP system operational experience offshore Brazil in 1,900 m of water," in Proceedings of the SPE/IADC Drilling Conference and Exhibition, Amsterdam, The Netherlands, 2009.

[7] L. C. Claassen, S. M. Hendriks, and G. H. T. Zijderveld, "Newbuild compact deepwater drillship designed for surface BOP system," in Proceedings of the Offshore Technology Conference 2010, OTC 2010, pp. 1391-1400, USA, May 2010. 
[8] American Petroleum Institute, API RP 16Q- Recommended Practice for Design, Selecfion, Operafion and Maintenance of Marine Drilling Riser Systems. Washington, DC, USA: American Petroleum Institute, 2001.

[9] J. C. Botke, "An Analysis of the Dynamics of Marine Risers," Tech. Rep., Delco Electronics, 1975.

[10] T. N. Gardner and M. A. Kotch, "Dynamic Analysis of Risers and Caissons by the Element Method," in Proceedings of the Offshore Technology Conference, Houston, TX, USA.

[11] J. M. Shaughnessy, W. T. Daugherty, R. L. Graff, and T. Durkee, "More Ultradeepwater Drilling Problems," in Proceedings of the SPE/IADC Drilling Conference, Feburary 2007.

[12] G. W. King, K. Burton, and T. Hodgson, "A coupled analysis approach to the assessment of marine drilling systems," SPE Drilling \& Completion, vol. 8, no. 2, pp. 131-137, 1993.

[13] K. Su, Z. Guan, and Y. Su, "Mechanical Stability Analysis of Subsea Wellhead for Deepwater Drilling," Oil Drilling Production Technology, vol. 30, no. 6, pp. 1-4, 2008.

[14] W. Yan, Z.-J. Chen, J.-G. Deng, H.-Y. Zhu, F.-C. Deng, and Z.-L. Liu, "Numerical method for subsea wellhead stability analysis in deepwater drilling," Ocean Engineering, vol. 98, pp. 50-56, 2015.

[15] C. K. Morooka, R. I. Tsukada, and D. M. Brandt, "Numerical simulations of ocean drilling system behavior with a surface or a subsea BOP in waves and current," in Proceedings of the 27th International Conference on Offshore Mechanics and Arctic Engineering, OMAE, pp. 469-476, Germany, June 2008.

[16] M. W. Dib, J. Lou, L. Zhu, and M. Bassey, "SBOP Drilling Enables Efficient Drilling in Extreme Water Depths," in Proceedings of the Offshore Technology Conference, Houston, TX, USA, 2009.

[17] S. S. Rao, Vibration of Continuous Systems, John Wiley Sons, Inc, Hoboken, NJ, USA, 2007.

[18] Tsinghua University, Mechanical Vibration. China Mechine Press, 1980.

[19] M. Novak, "Dynamic stiffness and damping of piles," Canadian Geotechnical Journal, vol. 11, no. 4, pp. 574-598, 1974.

[20] G. Gazetas and R. Dobry, "Horizontal response of piles in layered soils," Journal of Geotechnical Engineering, vol. 110, no. 1, pp. 20-40, 1984.

[21] T. Wang, X. Zhang, and W. Zhu, "Vessel Motion Effects on Nonlinear Dynamics of Deepwater Drilling Riser," Journal of Ship Mechanics, vol. 14, no. 6, pp. 606-617, 2010.

[22] R. M. Sexton and L. k. Agbezuge, "Random Wave and Vessel Motion Effects on Drilling Riser Dynamics," in Proceedings of the Offshore Technology Conference, Houston, Texas, 1976.

[23] C. Cui, H. Jiang, and Y.-H. Li, "Semi-analytical method for calculating vibration characteristics of variable cross-section beam," Journal of Vibration and Shock, vol. 31, no. 14, pp. 85-88, 2012. 


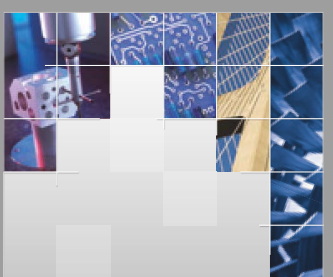

\section{Enfincering}
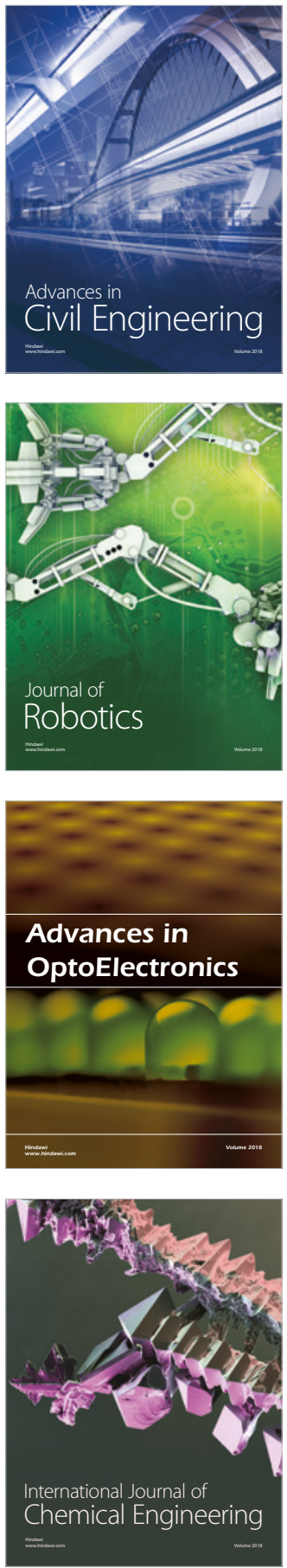

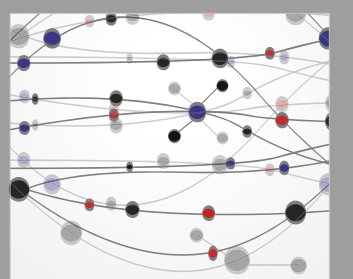

\section{Rotating \\ Machinery}

The Scientific World Journal

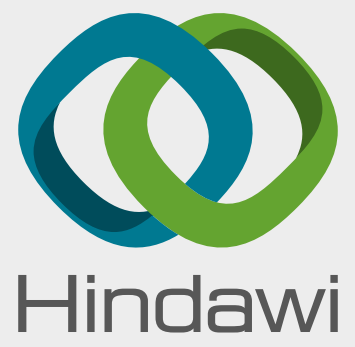

Submit your manuscripts at

www.hindawi.com
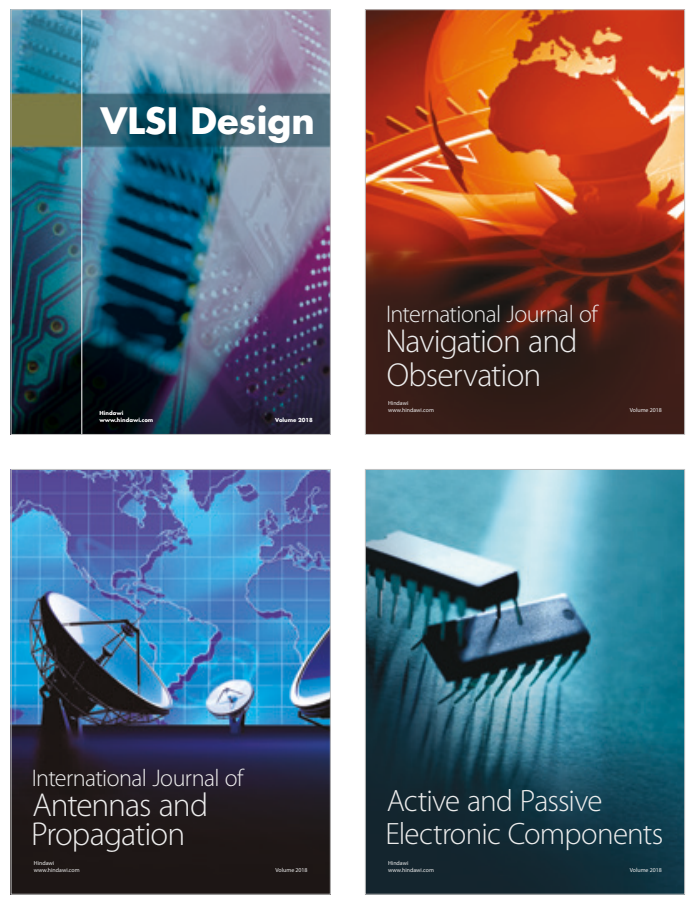
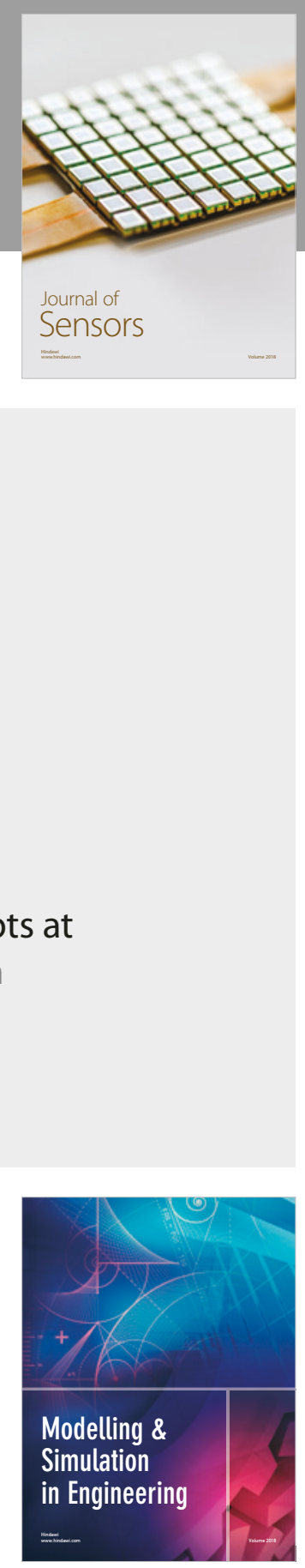

\section{Advances \\ Multimedia}
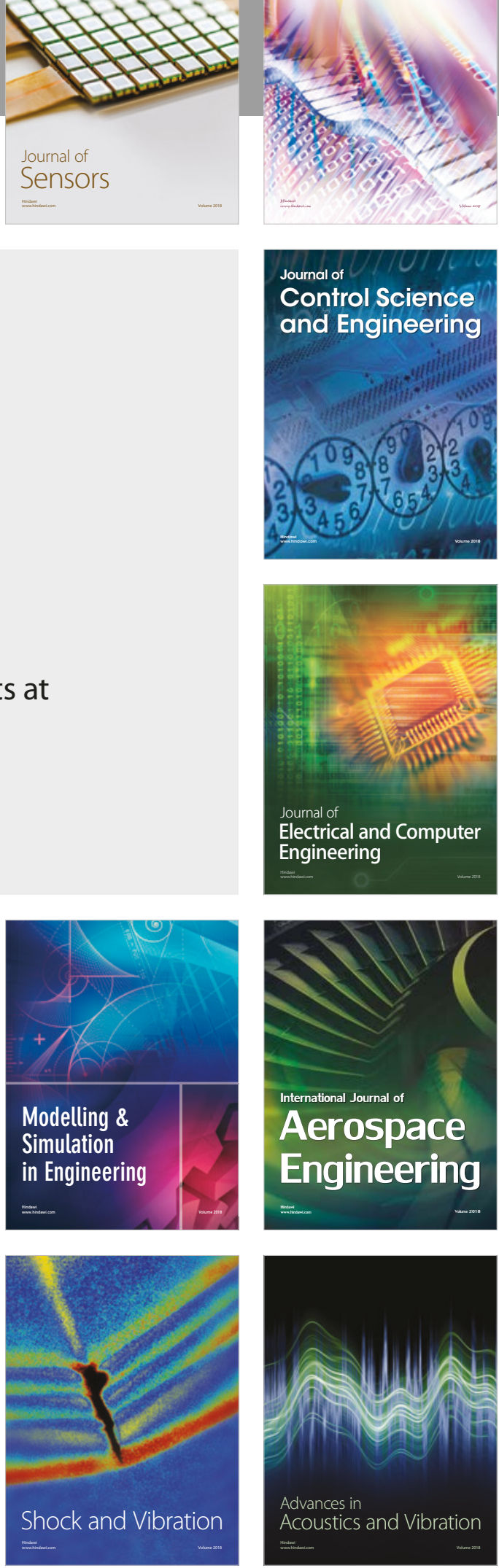